\title{
The effect of hyperoxia on central blood pressure in healthy subjects
}

Maciej Siński ${ }^{1}$, Jacek Lewandowski ${ }^{1}$, Anna Dobosiewicz ${ }^{2}$, Jacek Przybylski ${ }^{3}$, Piotr Abramczyk ${ }^{1}$, Zbigniew Gaciong ${ }^{1}$

\author{
${ }^{1}$ Department of Internal Medicine, Hypertension and Vascular Diseases, \\ Medical University of Warsaw, Warsaw, Poland \\ ${ }^{2}$ Department of Pulmonary Circulation and Thromboembolic Diseases, \\ Center of Postgraduate Medical Education, Otwock, Poland \\ ${ }^{3}$ Department of Biophysics and Physiology, Medical University of Warsaw, Warsaw, \\ Poland
}

Submitted: 8 December 2014

Accepted: 30 January 2015

Arch Med Sci 2016; 12, 5: 992-999

DOI: 10.5114 /aoms.2015.49038

Copyright (C) 2016 Termedia \& Banach

\section{Abstract}

Introduction: Hyperoxia increases total peripheral resistance by acting locally but also inhibits the activity of carotid body chemoreceptors. We studied the effect of hyperoxia on central pressure in normotensive subjects.

Material and methods: Medical air followed by $100 \%$ oxygen was provided to 19 subjects ( $12 / 7$ female/male, age $28.2 \pm 1.1$ years) for 15 min through a non-rebreather mask. Central blood pressure was then measured using applanation tonometry.

Results: After the first 2 min of hyperoxia, heart rate decreased significantly ( $65 \pm 2.6$ beats $/ \mathrm{min}$ vs. $61 \pm 2.1$ beats $/ \mathrm{min}, p=0.0002)$. Peripheral and central blood pressure remained unchanged, while hemoglobin oxygen saturation and subendocardial viability ratio index increased ( $97 \pm 0.4 \%$ vs. $99 \pm 0.2 \%, p=0.03 ; 168 \pm 8.4 \%$ vs. $180 \pm 8.2 \%, p=0.009$ ). After $15 \mathrm{~min}$ of $100 \%$ oxygen ventilation, heart rate and peripheral and central blood pressures remained unchanged from the first $2 \mathrm{~min}$. The augmentation index, augmentation pressure and ejection duration increased as compared to baseline values and those obtained at $2 \min (-5.1 \pm 2.9 \%$ vs. $-1.2 \pm 2.6 \%$, $p=0.005$ and $-4.6 \pm 2.7 \%$ vs. $-1.2 \pm 2.6 \%, p=0.0015 ;-1.3 \pm 0.7 \mathrm{~mm} \mathrm{Hg}$ vs. $-0.2 \pm 1.2 \mathrm{~mm} \mathrm{Hg}, p=0.003$ and $-1.1 \pm 0.7 \mathrm{~mm} \mathrm{Hg}$ vs. $-0.2 \pm 1.2 \mathrm{~mm} \mathrm{Hg}$, $p=0.012 ; 323 \pm 3.6 \mathrm{~ms}$ vs. $330 \pm 3.5 \mathrm{~ms}, p=0.0002$ and $326 \pm 3.5 \mathrm{~ms}$ vs. 330 $\pm 3.5 \mathrm{~ms}, p=0.021$, respectively).

Conclusions: The present study shows that hyperoxia does not affect central blood pressure in young healthy subjects and may improve myocardial blood supply estimated indirectly from applanation tonometry.

Key words: carotid body chemoreceptors, hyperoxia, central blood pressure.

\section{Introduction}

Oxygen supplementation is used widely used in the treatment of patients with acute circulatory and respiratory distress. Additionally, hyperoxia reduces the tonic activity of carotid body chemoreceptors [1-5]. The carotid body chemoreceptors attract attention as a possible therapeutic target in the treatment of heart failure and hypertension [6-9].

\author{
Corresponding author: \\ Jacek Lewandowski MD, PhD \\ Department of \\ Internal Medicine \\ Hypertension and \\ Vascular Diseases \\ Medical University \\ of Warsaw \\ 1a Banacha St \\ 01-461 Warsaw, Poland \\ Phone: +48 501109150 \\ Fax: +48 225992828 \\ E-mail: j_lewandowski@ \\ yahoo.com
}


Data on the hemodynamic effects of hyperoxia are not consistent across studies. In patients with heart failure, hyperoxia reduces cardiac output and increases total vascular resistance $[10,11]$. In patients after heart transplantation, the reduced tonic activity of carotid body chemoreceptors due to hyperoxia caused a decrease in blood pressure [4]. In patients with hypertension peripheral blood pressure values remained unchanged [2, 4] or decreased $[5,12]$ in response to hyperoxia. The recent AVOID trial with oxygen supplementation during acute coronary syndrome showed worse clinical outcomes in patients who were not hypoxic at the start of the study $[13,14]$. In the pilot study hyperoxia increased central blood pressure, with no effect on peripheral blood pressure values in the treated hypertensives [15].

In healthy individuals hyperoxia decreases heart rate and cardiac output and increases blood pressure and vascular resistance [16-20]. However, certain studies showed that hyperoxia did not affect blood pressure [16] or decreased blood pressure [3].

The mechanisms of the hemodynamic effects of hyperoxia are not fully explained. The inhibition of sympathetic activity due to the withdrawal of tonic activity of the carotid body chemoreceptors and the direct effect of hyperoxia on smooth muscle were suggested to be responsible for the observed changes in blood pressure [20].

The influence of hyperoxia on central aortic blood pressure has not yet been evaluated. Central blood pressure may differ from peripheral blood pressure values, and is affected by the elastic properties of peripheral arteries [21]. Furthermore, parameters of central aortic pressure may be a good surrogate for the effect of hyperoxia on arterial hemodynamics [21]. An estimation of central blood pressure could help in understanding the cardiovascular response to hyperoxic exposure. Therefore we evaluated both early (after the first $2 \mathrm{~min}$ ) and prolonged effects (after $15 \mathrm{~min}$ ) of acute hyperoxia on central blood pressure in healthy subjects.

\section{Material and methods}

\section{Subjects}

Nineteen healthy volunteers (12 female and 7 male; age: $28.2 \pm 1.1$ years; body mass index (BMI) $22.1 \pm 0.8 \mathrm{~kg} / \mathrm{m}^{2}$ ) were invited to participate in the study. All subjects underwent routine diagnostic evaluation in our clinic to exclude arterial hypertension, diabetes, respiratory disorders, as well as heart and vascular diseases. None of the participants were active smokers or were taking any medication. None of the female subjects were pregnant. The Ethical Committee of the Medical
University of Warsaw accepted the study protocol. All participants provided their informed consent.

\section{Study procedures}

All subjects were examined at midday, in a quiet room, in the supine position at ambient temperature of $20-21^{\circ} \mathrm{C}$. The subjects were instructed to take only a light breakfast in the morning. Prior to the placement of a non-rebreather mask all patients underwent baseline recordings (as defined below) for $10 \mathrm{~min}$, after which the subjects respired with $21 \%$ oxygen in nitrogen through a mask for 15 min and were subsequently ventilated with $100 \%$ oxygen for 15 min to induce hyperoxia. The flow rate through the non-rebreather mask was constant throughout the study at $10 \mathrm{l}$ min. The subjects were blind to the type and percentage of gas they were inspiring. Hemoglobin oxygen saturation $\left(\mathrm{SaO}_{2}\right)$ was monitored throughout the study (CapnoCheck Plus, Smith Medical International Ltd., Watford, Herts, UK).

\section{Assessment of hemodynamic responses}

Brachial blood pressure was measured with a certified automatic oscillometric device: NIS 2000 (ELMED, Augsburg, Germany). Central blood pressure and heart rate were determined using the SphygmoCor system (MM3 model, AtCor Medical, Sydney, Australia). SphygmoCor uses high fidelity applanation tonometry for the non-invasive registration of radial artery pressure waves and computer software for pressure wave analysis. The average pressure wave was calculated from 8-second recordings. The averaged pressure waves were accepted only when the variation of the peak and bottom pressures of individual pressure waves was < 10\%. The SphygmoCor device provides a quality index, which represents reproducibility of the waveform. Measurements were performed by two trained physicians (P.A. and A.D.). Intra-observer and inter-observer variability for these investigators based on 150 previously performed studies is $0 \pm 4 \%$ and $0 \pm 3 \%$ respectively. The visually acceptable recordings of a peripheral pulse waveform were allowed when measurements had a quality index (operator index) $>90$. The mean operator index was $93.5 \pm 1.6 \%$ in this study. The central pressure wave was automatically calculated from radial pressures by a built-in general transfer function [22, 23]. The aortic systolic, diastolic and mean blood pressures $(\mathrm{mm} \mathrm{Hg}$ ) were calculated from the recorded central waveforms. SphygmoCor makes it possible to determine other parameters from the central pressure wave. These are: time to first shoulder determined by the outgoing pressure wave $(T 1, \mathrm{~ms})$, time to the peak of the second shoulder determined by the reflected 
pressure wave (T2, ms), duration of absolute ejection (ED, ms), augmentation pressure (AP) defined as the difference between pressure values at $T 2$ and $T 1(\mathrm{~mm} \mathrm{Hg})$, and augmentation index (Al) defined as the quotient of augmentation pressure and central pulse pressure (PP) and expressed as a percentage (\%) (Figure 1). The augmentation index and augmentation pressure were normalized for a heart rate of 75 beats per minute. The subendocardial viability ratio (SEVR) was also evaluated from recorded central waveforms. The SEVR (also known as the Buckberg index) is an index of myocardial oxygen supply and demand, and is calculated by pulse wave analysis. Originally, SEVR is derived from pressures measured in the aorta and left ventricle $[24,25]$ and is defined as the ratio of the pressure-time integral in which the numerator is the diastolic pressure-time integral. The diastolic pressure-time integral (expressed in $\mathrm{mm} \mathrm{Hg} \times \mathrm{s}$ ) indicates subendocardial blood supply, whereas the systolic pressure-time integral (expressed in $\mathrm{mm} \mathrm{Hg} \times \mathrm{s}$ ) indicates myocardial contraction (oxygen consumption) [26]. In the study, SEVR was calculated using software provided by the producer. This software automatically calculates SEVR from diastolic/systolic aortic area.

\section{Statistical analysis}

During the session the subjects' central blood pressure was recorded at the end of the $21 \%$ oxygen respiration period $\left(P_{0}\right)$, after 2 min of hyper- oxia $\left(P_{1}\right)$ and once the 15 min hyperoxia period $\left(P_{2}\right)$ had ended. These time periods for recording peripheral and central blood pressure were selected so as to evaluate early responses to hyperoxia-induced carotid body deactivation [27, 28] and to determine the results of prolonged hyperoxia. Recording was performed at $P_{1}$ due to the fact that early hemodynamic effects of carotid body deactivation in previous observations had started within the $1^{\text {st }}$ min of exposure to hyperoxia [12] plus the time needed to perform the recording. A timeline representing the period of analyses is presented in Figure 2.

Our primary variable was the change in central systolic and diastolic blood pressure during the early stage of hyperoxic stimuli (at $2 \mathrm{~min}, P_{1}$ ). The size of the study group was determined by extrapolating the results of peripheral blood pressure changes, obtained in other studies [12, 20]. It was calculated that the study sample size of 19 subjects represented an $80 \%$ chance of detecting a $5 \mathrm{~mm} \mathrm{Hg}$ difference in systolic blood pressure before and after hyperoxic stimuli. The data were processed through a normality test (Shapiro-Wilk test) and then analyzed with repeated ANOVA or Friedman ANOVA tests for non-normal distribution. Differences between time points were tested post-hoc using the Fisher least significant difference (LSD) test. The Wilcoxon test with adjusted $p$-value was used as a post-hoc test for Friedman ANOVA. All data were expressed in mean values \pm

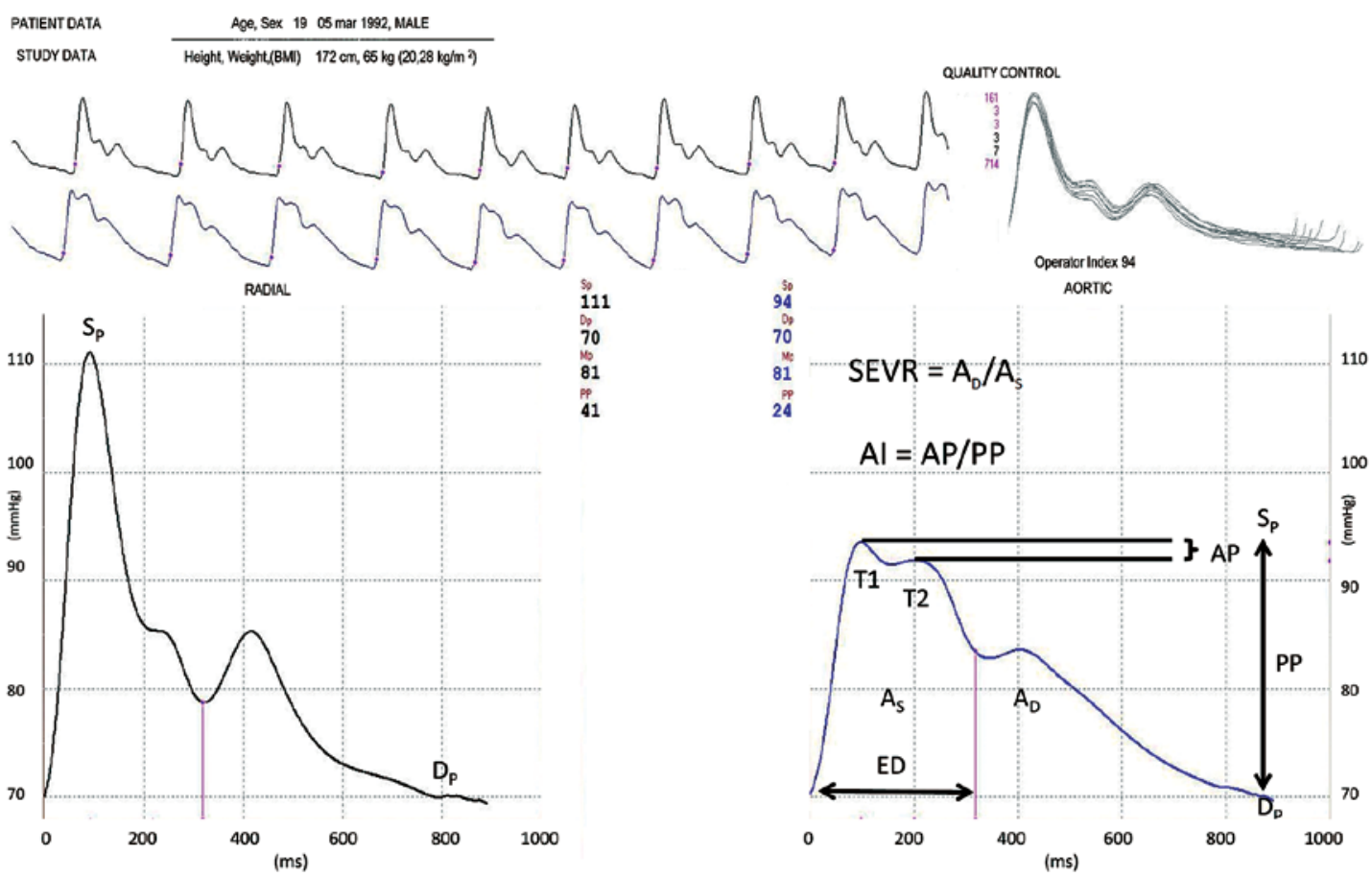

Figure 1. Parameters of central blood pressure presented on the original study recording

SEVR - subendocardial viability ratio, ED - ejection duration, $A P$ - augmentation pressure, $A l$ - augmentation index, $P P$ - pulse pressure, $A_{S}$ - area under the curve for systole, $A_{D}$ - area under the curve for diastole. 
SEM. The statistical analysis was performed using Statistica 10 software (StatSoft, Inc., Tulsa, USA).

\section{Results}

The baseline group characteristics are presented in Table I. For the primary variable, breathing $100 \%$ oxygen did not result in a significant change in central systolic and diastolic blood pressure between $P_{0}$ and $P_{1}$ (Table I). No changes were observed in the peripheral systolic and diastolic blood pressure values. Heart rate decreased significantly between $P_{0}$ and $P_{1}(65 \pm 2.6$ beats/min vs. $61 \pm 2.1$, beats $/ \mathrm{min}, p=0.0002$ ) (Table I). $\mathrm{SaO}_{2}$ and SEVR increased likewise ( $97 \pm 0.4 \%$ vs. $99 \pm 0.2 \%, p=0.03$; $168 \pm 8.4 \%$ vs. $181 \pm 8.2 \%, p=0.009$, respectively) (Figure 3, Table I). After 15 min of $100 \%$ oxygen ventilation, peripheral and central systolic and diastolic blood pressures remained unchanged (Table I). A further decrease in heart rate was not observed ( $61 \pm 2.1$ beats/min vs. $58 \pm 2.5$ beats/min, NS). Augmentation pressure, augmentation index and ejection duration increased after $15 \mathrm{~min}$ of breathing $100 \%$ oxygen, as compared to baseline values and values obtained at $P_{1}$ (Figure 3, Table I).

\section{Discussion}

The original finding of the study is that hyperoxia does not influence central aortic blood pres-

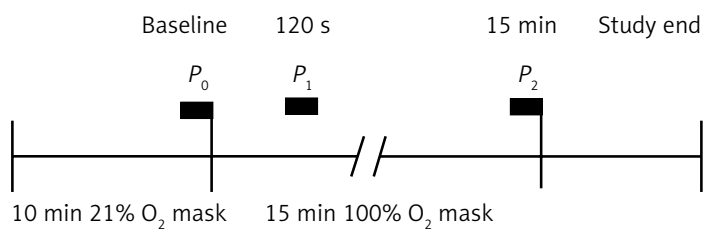

Figure 2. Experimental protocol

sure in healthy subjects. In the early phase of hyperoxia (first $2 \mathrm{~min}$ ) central and peripheral blood pressures did not change with increased $\mathrm{SaO}_{2}$. The present results are consistent with previous studies evaluating the early effects of hyperoxia on peripheral blood pressure. It is interesting that in hypertensive patients, blood pressure decreased in the early phase of hyperoxia, unlike in normotensive subjects [12, 28, 29]. The reason for this is unclear. It is possible that blood pressure decreases in hypertensive patients due to the inhibition of a carotid body chemoreflex, which is enhanced in hypertensive subjects, but not in normotensive subjects [30,31]. It is also known that early phase hyperoxia does not affect muscle sympathetic nerve activity (MSNA) in normotensive subjects, though it does reduce MSNA in hypertensive patients [2, 4]. In these studies microneurography was used, which is considered the most accurate and reproducible quantitative method for evaluation of activity of the sympathetic nervous system [32].

Table I. Effect of $100 \% \mathrm{O}_{2}$ breathing on the recorded parameters during study periods in normotensive subjects

\begin{tabular}{|c|c|c|c|c|c|c|}
\hline Parameter & $P_{0}$ & $P_{1}$ & $P_{2}$ & $P_{0}$ vs. $P_{1}$ & $P_{0}$ vs. $P_{2}$ & $P_{1}$ vs. $P_{2}$ \\
\hline Central SBP [mm Hg] & $97 \pm 2$ & $96 \pm 2$ & $96 \pm 2$ & NS & NS & NS \\
\hline Central DBP [mm Hg] & $72 \pm 2$ & $71 \pm 2$ & $71 \pm 2$ & NS & NS & NS \\
\hline Peripheral SBP [mm Hg] & $113 \pm 2$ & $113 \pm 2$ & $112 \pm 2$ & NS & NS & NS \\
\hline Peripheral DBP [mm Hg] & $71 \pm 2$ & $70 \pm 2$ & $70 \pm 2$ & NS & NS & NS \\
\hline $\mathrm{HR}$ [beat/min] & $65 \pm 3$ & $61 \pm 2$ & $58 \pm 3$ & 0.0002 & 0.00001 & NS \\
\hline $\mathrm{ED}[\mathrm{ms}]$ & $323 \pm 4$ & $326 \pm 4$ & $330 \pm 4$ & NS & 0.0002 & 0.021 \\
\hline $\mathrm{AP}[\mathrm{mm} \mathrm{Hg}]$ & $-1.3 \pm 0.7$ & $-1.1 \pm 0.7$ & $-0.2 \pm 0.6$ & NS & 0.003 & 0.012 \\
\hline AP (75) [mm Hg] & $-2.6 \pm 0.8$ & $-2.8 \pm 0.7$ & $-2.1 \pm 0.7$ & NS & NS & NS \\
\hline $\mathrm{Al}(\%)$ & $-5.1 \pm 2.9$ & $-4.6 \pm 2.7$ & $-1.2 \pm 2.6$ & NS & 0.005 & 0.0015 \\
\hline $\mathrm{Al}(75)(\%)$ & $-9.8 \pm 3.0$ & $-11.2 \pm 2.7$ & $-7.8 \pm 2.8$ & NS & NS & NS \\
\hline$T 1[\mathrm{~ms}]$ & $109 \pm 3$ & $114 \pm 4$ & $114 \pm 3$ & NS & NS & NS \\
\hline$T 2[\mathrm{~ms}]$ & $208 \pm 6$ & $220 \pm 5$ & $219 \pm 6$ & NS & NS & NS \\
\hline SEVR (\%) & $168 \pm 8$ & $181 \pm 8$ & $189 \pm 10$ & 0.009 & 0.00003 & NS \\
\hline $\mathrm{SaO}_{2}(\%)$ & $97 \pm 0.4$ & $99 \pm 0.2$ & $99 \pm 0.3$ & 0.005 & 0.005 & NS \\
\hline RR [breath/min] & $14 \pm 0.7$ & $12 \pm 0.7$ & $12 \pm 0.7$ & NS & NS & NS \\
\hline
\end{tabular}

$P_{0}, P_{1}$ and $P_{2}$ are means \pm SEM of the parameters recorded at baseline and after 2 and 15 min of $100 \%$ oxygen breathing, SaO hemoglobin oxygen saturation, ED - ejection duration, AP - augmentation pressure, Al-augmentation index, SEVR - subendocardial viability ratio, T1 - time to first shoulder determined by outgoing pressure wave, T2-time to the peak of the second shoulder determined by the reflected pressure wave. 

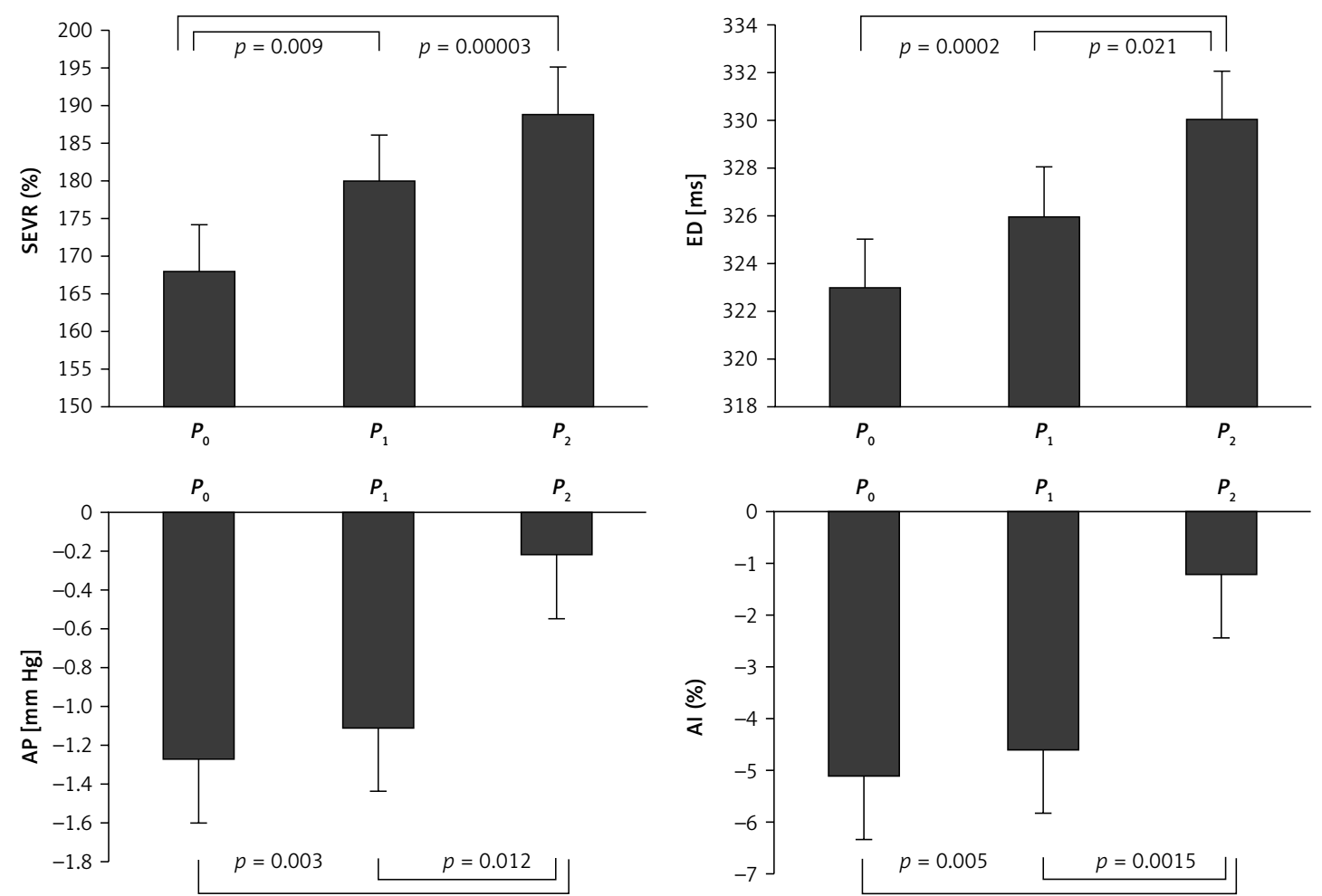

Figure 3. Subendocardial viability ratio (SEVR), ejection duration (ED), augmentation pressure (AP) and augmentation index $(\mathrm{Al})$ at baseline $\left(P_{0}\right)$ and after $2\left(P_{1}\right)$ and $15 \mathrm{~min}\left(P_{2}\right)$ of $100 \%$ oxygen breathing. Data presented as means \pm SEM

The results of the present study show that longer exposure to hyperoxic stimuli did not affect central aortic pressure and peripheral pressure. This observation is important. The effect of hyperoxia on central blood pressure in healthy subjects has not yet been investigated, while results concerning the effect of hyperoxia on peripheral blood pressure differ substantially across studies. During longer hyperoxic exposure, peripheral blood pressure increased [18-20] or no effects were reported $[2,4,12,16,33,34]$. The difference in the results obtained in our study from previous reports may be due to the difference in subject age, sex and/ or duration of hyperoxic exposure. Despite these differences, it is unclear why in the present study central and peripheral blood pressures remained unchanged during prolonged hyperoxia. It is documented that prolonged hyperoxia increases total peripheral resistance [16] and reduces heart rate in healthy subjects $[18,35]$. It is also known that hyperoxia may reduce stroke volume or depress heart muscle contractility [16, 35, 36]. In the present study, heart rate actually decreased. Although peripheral resistance and stroke volume were not evaluated, the augmentation index and augmentation pressure were calculated from the central pressure wave. The values of both indices increased between periods $P_{1}$ and $P_{2}$ (Figure 3). This may reflect increased peripheral resistance/increased arterial wall stiffness during prolonged hyperoxia.
The absence of blood pressure changes due to hyperoxia may be explained in different ways. We can assume that the increase in total peripheral resistance caused by hyperoxia is compensated by a reduced heart rate. It is less likely that the decrease in stroke volume is responsible for unchanged central blood pressure, not unlike a similar experimental model where no differences in stroke volume were observed in healthy normotensive subjects [12]. We can also speculate that the unchanged central and peripheral blood pressure is the result of antagonistic mechanisms in which hyperoxia influences peripheral vasculature: withdrawal of tonic chemoreceptor activity causing a decrease in the total peripheral resistance and the direct effect of high $\mathrm{pO}_{2}$ increasing total peripheral resistance.

Hyperoxia within the first 2 min caused an increase in SEVR. Based on applanation tonometry, SEVR differs from the Buckberg and Hoffman method [24, 25], and the results should be analyzed with caution. The SEVR is calculated from the central pressure wave. Moreover, the central pressure wave is a result of the calculation made when applying a generalized transfer function on the measurement taken at the radial artery. However, there is a sound correlation between the central pressure wave obtained using a transfer function and the pressure wave obtained invasively $[22,37]$. When using a generalized transfer func- 
A

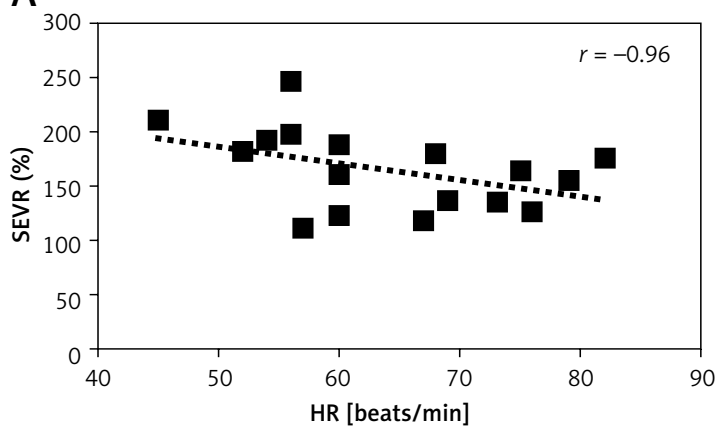

C

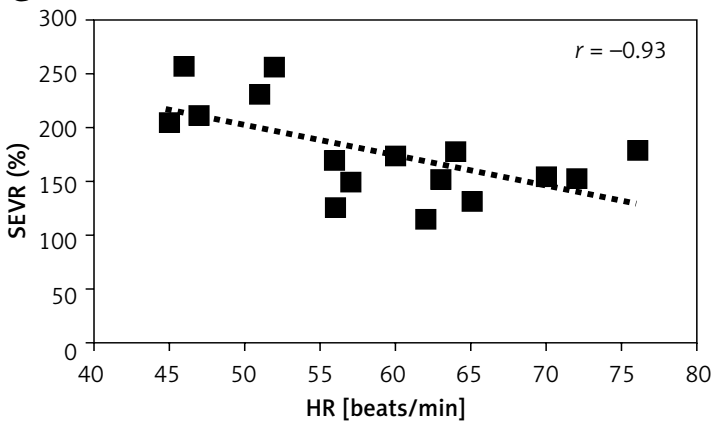

tion it is assumed that arterial vasculature properties are similar in different subjects, but vary according to age, arterial pressure, body size and health status [38]. In the current study, subjects were of similar age, body mass index, body surface area and resting blood pressure. Although SEVR is an indirect quantification, it is considered by other authors as a valid, sensitive and reproducible measure of the balance between oxygen demand and supply and a marker of subendocardial perfusion [26, 39-42]. Recently, a correlation was also found between SEVR and the coronary flow reserve measured during coronarography [26].

The SEVR correlates with heart rate, and in the current study such an association was observed before and after hyperoxic stimulation (Figure 4). It can be postulated that the changes observed in SEVR are secondary to the decrease in heart rate. However, SEVR also increases after nitroglycerin infusion, thus implying that SEVR may improve as a result of vasodilatation [43]. The results of the AVOID study did not show any beneficial effects of oxygen supplementation in patients with myocardial infarction $[13,14]$. It needs to be clarified whether the observed increase in SEVR after inspiring $100 \%$ oxygen is only a transient effect and is present only in the normal coronary vasculature.

The present study has some limitations. We did not use a control group inspiring medical air. Previous studies with a control group showed no hemodynamic effects of inspiration in healthy subjects $[2,11]$. In the present study, the values obtained while breathing medical air through the mask were used as a control for breathing 100\%

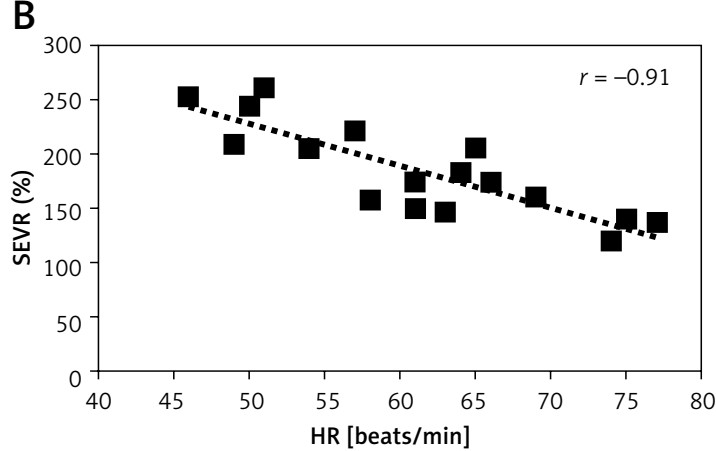

Figure 4. Correlation between subendocardial viability ratio (SEVR) and heart rate (HR) at baseline $\left(P_{0}\right)$ $\left(\right.$ A) and after $2\left(P_{1}\right)(B)$ and 15 min $\left(P_{2}\right)($ C) of $100 \%$ oxygen breathing

oxygen. Such a design has been used in other studies $[12,20,44]$.

Total peripheral resistance, stroke volume and cardiac output were not measured in the present study. These parameters were evaluated recently in a normotensive population using a similar experimental design [12].

The study group was composed of more female subjects than male subjects. It is not well established how hemodynamic parameters differ across sex in young subjects. Circulatory hemodynamics may differ according to menstrual cycle phase $[45,46]$, but no change in blood pressure or heart rate was observed across cycle phases. It is rather unlikely for the results of the study to be affected by sex or menstrual cycle phase.

In conclusion, the present study shows that central blood pressure in healthy subjects does not change after being exposed to hyperoxia. This may be due to a decrease in heart rate and two antagonistic mechanisms, in which hyperoxia has an impact on hemodynamics. The study results also demonstrate that hyperoxia in healthy subjects may improve myocardial blood supply, estimated indirectly using applanation tonometry.

\section{Acknowledgments}

The study was supported by an internal grant (1WS/2014) from the Medical University of Warsaw.

\section{Conflict of interest}

The authors declare no conflict of interest. 
References

1. Seals DR, Johnson DG, Fregosi RF. Hyperoxia lowers sympathetic activity at rest but not during exercise in humans. Am J Physiol 1991; 260: R873-8.

2. Sinski M, Lewandowski J, Przybylski J, et al. Tonic activity of carotid body chemoreceptors contributes to the increased sympathetic drive in essential hypertension. Hypertens Res 2012; 35: 487-91.

3. Narkiewicz K, van de Borne PJ, Montano N, Dyken ME, Phillips BG, Somers VK. Contribution of tonic chemoreflex activation to sympathetic activity and blood pressure in patients with obstructive sleep apnea. Circulation 1998; 97: 943-5.

4. Ciarka A, Najem B, Cuylits N, et al. Effects of peripheral chemoreceptors deactivation on sympathetic activity in heart transplant recipients. Hypertension 2005; 45: 894-900.

5. Izdebska E, Cybulska I, Sawicki M, Izdebski J, Trzebski A. Postexercise decrease in arterial blood pressure, total peripheral resistance and in circulatory responses to brief hyperoxia in subjects with mild essential hypertension. J Hum Hypertens 1998; 12: 855-60.

6. McBryde FD, Abdala AP, Hendy EB, et al. The carotid body as a putative therapeutic target for the treatment of neurogenic hypertension. Nat Commun 2013; 4: 2395.

7. Paton JF, Ratcliffe L, Hering D, Wolf J, Sobotka PA, Narkiewicz K. Revelations about carotid body function through its pathological role in resistant hypertension. Curr Hypertens Rep 2013; 15: 273-80.

8. Paton JF, Sobotka PA, Fudim M, et al. The carotid body as a therapeutic target for the treatment of sympathetically mediated diseases. Hypertension 2013; 61: 5-13.

9. Niewinski P, Janczak D, Rucinski A, et al. Carotid body removal for treatment of chronic systolic heart failure. Int J Cardiol 2013; 168: 2506-9.

10. Haque WA, Boehmer J, Clemson BS, Leuenberger UA, Silber DH, Sinoway LI. Hemodynamic effects of supplemental oxygen administration in congestive heart failure. J Am Coll Cardiol 1996; 27: 353-7.

11. Mak S, Azevedo ER, Liu PP, Newton GE. Effect of hyperoxia on left ventricular function and filling pressures in patients with and without congestive heart failure. Chest 2001; 120: 467-73.

12. Sinski M, Lewandowski J, Przybylski J, et al. Deactivation of carotid body chemoreceptors by hyperoxia decreases blood pressure in hypertensive patients. Hypertens Res 2014; 37: 858-62.

13. Stub D, Smith K, Bernard S, et al. A randomized controlled trial of oxygen therapy in acute myocardial infarction Air Verses Oxygen In myocarDial infarction study (AVOID Study). Am Heart J 2012; 163: 339-45.

14. Stub D, Smith K, Bernard S, et al. Air Verses Oxygen In myocarDial infarction study (AVOID Study). American Heart Association (AHA) 2014 Scientific Sessions, November 15-19, 2014.

15. Dobosiewicz A, Abramczyk P, Sinski M. Hyperoxia increases central aortic pressure in hypertensive patients. XXVIII European Meeting of International Society for Heart Research, International Proceedings. 2008; 33-6.

16. Bak Z, Sjoberg F, Rousseau A, Steinvall I, JanerotSjoberg B. Human cardiovascular dose-response to supplemental oxygen. Acta Physiol (Oxf) 2007; 191: 15-24.

17. Daly WJ, Bondurant S. Effects of oxygen breathing on the heart rate, blood pressure, and cardiac index of normal men: resting, with reactive hyperemia, and after atropine. J Clin Invest 1962; 41: 126-32.
18. Gole Y, Gargne O, Coulange M, et al. Hyperoxia-induced alterations in cardiovascular function and autonomic control during return to normoxic breathing. Eur J Appl Physiol 2011; 111: 937-46.

19. Waring WS, Thomson AJ, Adwani SH, et al. Cardiovascular effects of acute oxygen administration in healthy adults. J Cardiovasc Pharmacol 2003; 42: 245-50.

20. Graff B, Szyndler A, Czechowicz K, et al. Relationship between heart rate variability, blood pressure and arterial wall properties during air and oxygen breathing in healthy subjects. Auton Neurosci 2013; 178: 60-6.

21. Williams B, Lacy PS, Thom SM, et al. Differential impact of blood pressure-lowering drugs on central aortic pressure and clinical outcomes: principal results of the Conduit Artery Function Evaluation (CAFE) study. Circulation 2006; 113: 1213-25.

22. Chen CH, Nevo E, Fetics B, et al. Estimation of central aortic pressure waveform by mathematical transformation of radial tonometry pressure. Validation of generalized transfer function. Circulation 1997; 95: 1827-36.

23. Sharman JE, Lim R, Qasem AM, et al. Validation of a generalized transfer function to noninvasively derive central blood pressure during exercise. Hypertension 2006; 47: 1203-8.

24. Buckberg GD, Fixler DE, Archie JP, Hoffman JI. Experimental subendocardial ischemia in dogs with normal coronary arteries. Circ Res 1972; 30: 67-81.

25. Hoffman JI, Buckberg GD. The myocardial supply:demand ratio - a critical review. Am J Cardiol 1978; 41: 327-32.

26. Tsiachris D, Tsioufis C, Syrseloudis D, et al. Subendocardial viability ratio as an index of impaired coronary flow reserve in hypertensives without significant coronary artery stenoses. J Hum Hypertens 2012; 26: 64-70.

27. Zapata P, Larrain C, Rivera MA, Calderon C. Cardiovascular responses to hyperoxic withdrawal of arterial chemosensory drive. Adv Exp Med Biol 2009; 648: 290-7.

28. Izdebska E, Izdebski J, Trzebski A. Hemodynamic responses to brief hyperoxia in healthy and in mild hypertensive human subjects in rest and during dynamic exercise. J Physiol Pharmacol 1996; 47: 243-56.

29. Izdebska E, Izdebski J, Cybulska I, Makowiecka-Ciesla M, Trzebski A. Moderate exercise training reduces arterial chemoreceptor reflex drive in mild hypertension. J Physiol Pharmacol 2006; 57 Suppl. 11: 93-102.

30. Trzebski A, Tafil M, Zoltowski M, Przybylski J. Increased sensitivity of the arterial chemoreceptor drive in young men with mild hypertension. Cardiovasc Res 1982; 16: 163-72.

31. Tafil-Klawe M, Trzebski A, Klawe J, Palko T. Augmented chemoreceptor reflex tonic drive in early human hypertension and in normotensive subjects with family background of hypertension. Acta Physiol Pol 1985; 36: 51-8.

32. Zygmunt A, Stanczyk J. Methods of evaluation of autonomic nervous system function. Arch Med Sci 2010; 6: 11-8.

33. Milone SD, Newton GE, Parker JD. Hemodynamic and biochemical effects of $100 \%$ oxygen breathing in humans. Can J Physiol Pharmacol 1999; 77: 124-30.

34. Larsson A, Uusijarvi J, Eksborg S, Lindholm P. Tissue oxygenation measured with near-infrared spectroscopy during normobaric and hyperbaric oxygen breathing in healthy subjects. Eur J Appl Physiol 2010; 109: 757-61.

35. Lund VE, Kentala E, Scheinin $\mathrm{H}$, et al. Heart rate variability in healthy volunteers during normobaric and hyperbaric hyperoxia. Acta Physiol Scand 1999; 167: 29-35.

36. Molenat F, Boussuges A, Grandfond A, et al. Haemodynamic effects of hyperbaric hyperoxia in healthy volun- 
teers: an echocardiographic and Doppler study. Clin Sci (Lond) 2004; 106: 389-95.

37. Karamanoglu M, O'Rourke MF, Avolio AP, Kelly RP. An analysis of the relationship between central aortic and peripheral upper limb pressure waves in man. Eur Heart J 1993; 14: 160-7.

38. O'Rourke MF, Pauca A, Jiang XJ. Pulse wave analysis. $\mathrm{Br}$ J Clin Pharmacol 2001; 51: 507-22.

39. Nichols W, O'Rourke M. McDonald's blood flow in arteries: theoretical, experimental and clinical principles. $5^{\text {th }}$ ed. Edward Arnold, London 2005.

40. Siebenhofer A, Kemp C, Sutton A, Williams B. The reproducibility of central aortic blood pressure measurements in healthy subjects using applanation tonometry and sphygmocardiography. J Hum Hypertens 1999; 13: 625-9.

41. Wilkinson IB, Fuchs SA, Jansen IM, et al. Reproducibility of pulse wave velocity and augmentation index measured by pulse wave analysis. J Hypertens 1998; 16: 2079-84.

42. Oliveros RA, Boucher CA, Haycraft GL, Beckmann CH. Myocardial oxygen supply-demand ratio: a validation of peripherally vs centrally determined values. Chest 1979; 75: 693-6.

43. Prisada OV, Covic A, Arghiri E, Cernomaz A, Ungureanu G. Pulse pressure, arterial compliance and Buckberg index in hypertensive patients treated with nebivolol and nitrates. Rev Med Chir Soc Med Nat lasi 2007; 111: 352-7.

44. Litchfield KN, Harten JM, Anderson KJ, Kinsella J, McGrady EM. Effects of normobaric hyperoxia on haemodynamic parameters of healthy full-term parturients. Anaesthesia 2007; 62: 931-5.

45. Hirshoren N, Tzoran I, Makrienko I, et al. Menstrual cycle effects on the neurohumoral and autonomic nervous systems regulating the cardiovascular system. J Clin Endocrinol Metab 2002; 87: 1569-75.

46. Fu Q, VanGundy TB, Shibata S, Auchus RJ, Williams GH, Levine BD. Menstrual cycle affects renal-adrenal and hemodynamic responses during prolonged standing in the postural orthostatic tachycardia syndrome. Hypertension 2010; 56: 82-90. 